OPEN ACCESS

Edited by:

Weihua Chen,

Zhengzhou University, China

Reviewed by:

Liwei Mi,

Zhongyuan University of

Technology, China

Xifei Li,

Xi'an University of Technology, China

Yufeng Zhao,

Shanghai University, China

*Correspondence:

Tianjing Wu

twu@xtu.edu.cn

Yong Liu

yonliu@csu.edu.cn

Specialty section: This article was submitted to

Electrochemistry,

a section of the journal

Frontiers in Chemistry

Received: 07 February 2020

Accepted: 23 April 2020

Published: 04 June 2020

Citation:

Jing $M$, Wu T, Zhou Y, Li X and Liu Y (2020) Nitrogen-Doped Graphene via In-situ Alternating Voltage Electrochemical Exfoliation for

Supercapacitor Application

Front. Chem. 8:428.

doi: 10.3389/fchem.2020.00428

\section{Nitrogen-Doped Graphene via In-situ Alternating Voltage Electrochemical Exfoliation for Supercapacitor Application}

\author{
Mingjun Jing ${ }^{1,2}$, Tianjing $W^{1,2 *}$, Yazheng Zhou ${ }^{2}$, Xilong $L_{i}^{2}$ and Yong Liu ${ }^{1 *}$ \\ ${ }^{1}$ State Key Laboratory of Powder Metallurgy, Central South University, Changsha, China, ${ }^{2}$ Department of Chemistry, \\ Xiangtan University, Xiangtan, China
}

Doping heteroatom, an effective way to enhance the electrochemical performances of graphene, has received wide attention, especially related to nitrogen. Alternating voltage electrochemical exfoliation, as a low cost and green electrochemical approach, has been developed to construct in-situ N-doped graphene (N-Gh) material. The N-Gh presents a much higher capacity than that of pure graphene prepared via the same method, which might be attributed to the introduction of nitrogen, which has much more effects and a disordered structure. As-prepared N-Gh exhibits a low O/C ratio that is helpful in maintaining high electrical conductivity. And the effects and disorder structure are also conductive to reduce the overlaps of graphene layers. A symmetric supercapacitor assembled with $\mathrm{N}$-Gh electrodes displays a satisfactory rate behavior and long cycling stability (92.3\% retention after 5,000 cycles).

Keywords: $\mathrm{N}$-doped graphene, alternating voltage, electrochemical exfoliation, electrochemical performances, supercapacitors

\section{INTRODUCTION}

Graphene exhibits exceptional electronic conductive ability and carrier mobility due to its unique quantum Hall effect on a honeycomb sp ${ }^{2}$ carbon lattice. Because of this, it became one of the most significant candidate materials for next-generation electronic and energy storage devices (Novoselov et al., 2004; Low et al., 2013; Gong et al., 2016). It is important to note that heteroatomdoped graphene might be better applied to supercapacitors through creating defects or embedding impurities. Among the various kinds of heteroatom-doped graphene materials, $\mathrm{N}$ atom is a general nominee because of its atomic size similarity to the carbon atom and unique valence electrons that generate a stable covalent bonds structure with adjacent C atoms (Low et al., 2013; Chaban and Prezhdo, 2015; Xu et al., 2018). Meanwhile, nitrogen atoms in N-doped graphene materials could become a redox active center, which might induce pseudocapacitance to increase the specific capacitance of materials (Luo et al., 2013; Yang et al., 2016). Hence, N-doped graphene or N-doped graphene-based composite materials are getting more and more attention.

In situ doping can be favorable for the formation of homogeneous doping (Qu et al., 2010; Yang et al., 2016). Some approaches have been developed to construct N-doped graphene. For example, 
$\mathrm{N}$-graphene has been obtained via the chemical vapor deposition (CVD) method using a nitrogen-containing mixed gas (Bulusheva et al., 2017; Bu et al., 2018). Additionally, Ngraphene also can be formed through the segregation growth approach (Zhang et al., 2011). However, most of these methods usually require expensive devices, multistep transfer processes, or result in a low yield. At present, developing a green and low cost method to prepare mass production of $\mathrm{N}$-doped graphene is still a major challenge.

There are several methods for graphene preparation, such as chemical vapor deposition (Suk et al., 2011), epitaxial growth (Yang W. et al., 2013), mechanical exfoliation (Yi and Shen, 2015), chemical exfoliation (Liu and Wang, 2011), electrochemical exfoliation (Yang et al., 2015; Bakunin et al., 2019), and so on. It is worth noting that electrochemical exfoliation has been deemed a useful technique in producing high-quality graphene on a large scale owing to it being environmentally friendly, low cost, and requiring only simple operations (Low et al., 2013; Ejigu et al., 2019). Two electrochemical types, cathodic and anodic methods, have been mainly performed in electrochemical exfoliation with graphite as a working electrode. On the one hand, cathodic exfoliation with the graphite material as a cathode usually takes place in organic solvents (Yang Y. et al., 2013; Taheri Najafabadi and Gyenge, 2015). This process typically needs some intercalates cations from the electrolyte, such as alkylammonium salts, ionic liquids, molten salts, and so on. On the other hand, anodic exfoliation is typically carried out in aqueous electrolytes with graphite as an anode (Parvez et al., 2014). The main issue of this method is the requirement of a high positive voltage (about a few tens of volts) in the electrochemical process, which might induce structural degradation and oxidation of the carbon lattice. Recently, a novel alternating voltage electrochemical exfoliation approach has been applied to prepare few-layer graphene flakes in aqueous electrolytes (Jing et al., 2015). Compared with the direct voltage exfoliation, the degree of oxidation of the carbon lattice can be reduced in the alternative redox process. And the two graphite electrodes are used as working electrodes during the alternating voltage process, which is conducive to improving the exfoliation efficiency.

Electrolyte solution is one of the key factors in all types of electrochemical exfoliation methods. $\mathrm{Li}$ salts as cathodic exfoliation electrolyte organic solution can release $\mathrm{Li}^{+}$ions that are reversibly intercalated into the inner spacing of graphite (Low et al., 2013). Aqueous $\mathrm{H}_{2} \mathrm{SO}_{4}$ solution as anodic exfoliation electrolyte system can produce oxygen radicals (O.) and hydroxyl $(\mathrm{OH} \cdot)$ to open boundaries, which is helpful in facilitating $\mathrm{SO}_{4}^{2-}$ intercalation, and then releasing $\mathrm{SO}_{2}$ to expand the interlayer distance of graphite (Yang et al., 2015). Inorganic salts aqueous solutions (such as $\left(\mathrm{NH}_{4}\right)_{2} \mathrm{SO}_{4}$ ) as anodic exfoliation electrolyte system shows a similar electrochemical mechanism in $\mathrm{H}_{2} \mathrm{SO}_{4}$ solution, except for the existence of $\mathrm{OH}^{-}$ions at the edge sites and grain boundaries (Zabihi et al., 2019). Aqueous $\mathrm{NaOH} / \mathrm{H}_{2} \mathrm{O}_{2}$ solution has also been utilized during anodic electrochemical exfoliation, which could generate $\mathrm{OH}^{-}$and $\mathrm{O}_{2}^{2-}$ intercalation ions and appears to result in $\mathrm{NaOH}$-induced electrochemical reduction of the oxygen functional groups of graphene (Rao et al., 2014). In addition, a range of reductive agents [such as sodium borohydride, (2,2,6,6-tetramethylpiperidin-1-yl]oxyl, ascorbic acid, and so on) as additives in electrolyte solution can improve the atomic ratio of $\mathrm{C} / \mathrm{O}$ and control the exfoliation process ( $\mathrm{Rao}$ et al., 2014). All these previous studies further indicate that the composition of electrolyte solution could mainly influence the functional groups, defects, atomic ratio of $\mathrm{C} / \mathrm{O}$, and yield of graphene. Based on the above analysis, in-situ nitrogen doping approaches might be achieved via adding nitrogen compounds into electrolyte solution during the electrochemical exfoliation of graphite. At present, few nitrogen compounds as additives (protic ionic liquid ethylammonium nitrate, ammonia, and natural biocompatible glycine) have been discussed to produce $\mathrm{N}$-doped graphene in an anodic electrochemical exfoliation process (Usachov et al., 2011; Wang et al., 2012). But the related research is still poor, especially utilizing an alternating voltage electrochemical technique.

In this study, the alternating voltage electrochemical technique has been successfully applied to in-situ construct Ndoped graphene (N-Gh) on a large scale by adding ammonium chloride salt to $\mathrm{NaOH}$ aqueous solution. Compared with as-prepared pure graphene $(\mathrm{Gh})$ utilizing the same process, the N-Gh sample presents a larger size and much more effects. And the electrochemical properties of N-Gh have been investigated in three-electrode and two-electrode systems. The $\mathrm{N}$-Gh sample reveals a satisfactory rate behavior and long cycling stability.

\section{EXPERIMENTAL SECTION}

\section{Synthesis of N-Doped Graphene Electrode Material}

Alternating voltage electrochemical exfoliation was fabricated with a two-electrode system utilizing two graphite rods as working electrodes. $\mathrm{N}$-doped graphene $(\mathrm{N}-\mathrm{Gh})$ was prepared in $3 \mathrm{M} \mathrm{NaOH}$ and $3 \mathrm{M} \mathrm{NH} \mathrm{NH}_{4} \mathrm{Cl}$ mixed aqueous solution. Both graphite rods were exfoliated via $5.0 \mathrm{~V}$ alternating voltage $(50 \mathrm{~Hz}, \quad$ YK-BP81005 regulator transformer) for $5 \mathrm{~h}$. Then the as-exfoliated substrate was separated, and further washed using distilled water until the $\mathrm{pH}$ value was close to 7 . At last, the N-Gh sample was obtained via the freeze-dried method. Pure graphene (Gh) was also put in $3 \mathrm{M} \mathrm{NaOH}$ aqueous solution under the same preparation conditions.

\section{Materials Characterization}

The phase character of materials was studied via the $\mathrm{X}$ ray diffractometer (XRD, Rigaku $\mathrm{D} / \mathrm{max} 2550 \mathrm{VB}^{+}$) from 10 to $80^{\circ}$ at $5^{\circ} \mathrm{min}^{-1}$ with $\mathrm{Cu} \mathrm{K} \alpha$ radiation. The raman spectra of the as-prepared products were collected using a Raman spectrometer (HORIBA Labram HR Evolution). The morphology of the as-obtained materials were explored through scanning electron microscopy (SEM, JSM-6510LV) and transmission electron microscopy (TEM, JEM-2100F). Furthermore, the atomic arrangement was studied utilizing high-resolution transmission electron microscopy (HRTEM, JEM-2100F). Then, FT-IR spectrophotometer (AVTATAR, 370) was applied to test the surface functional groups 


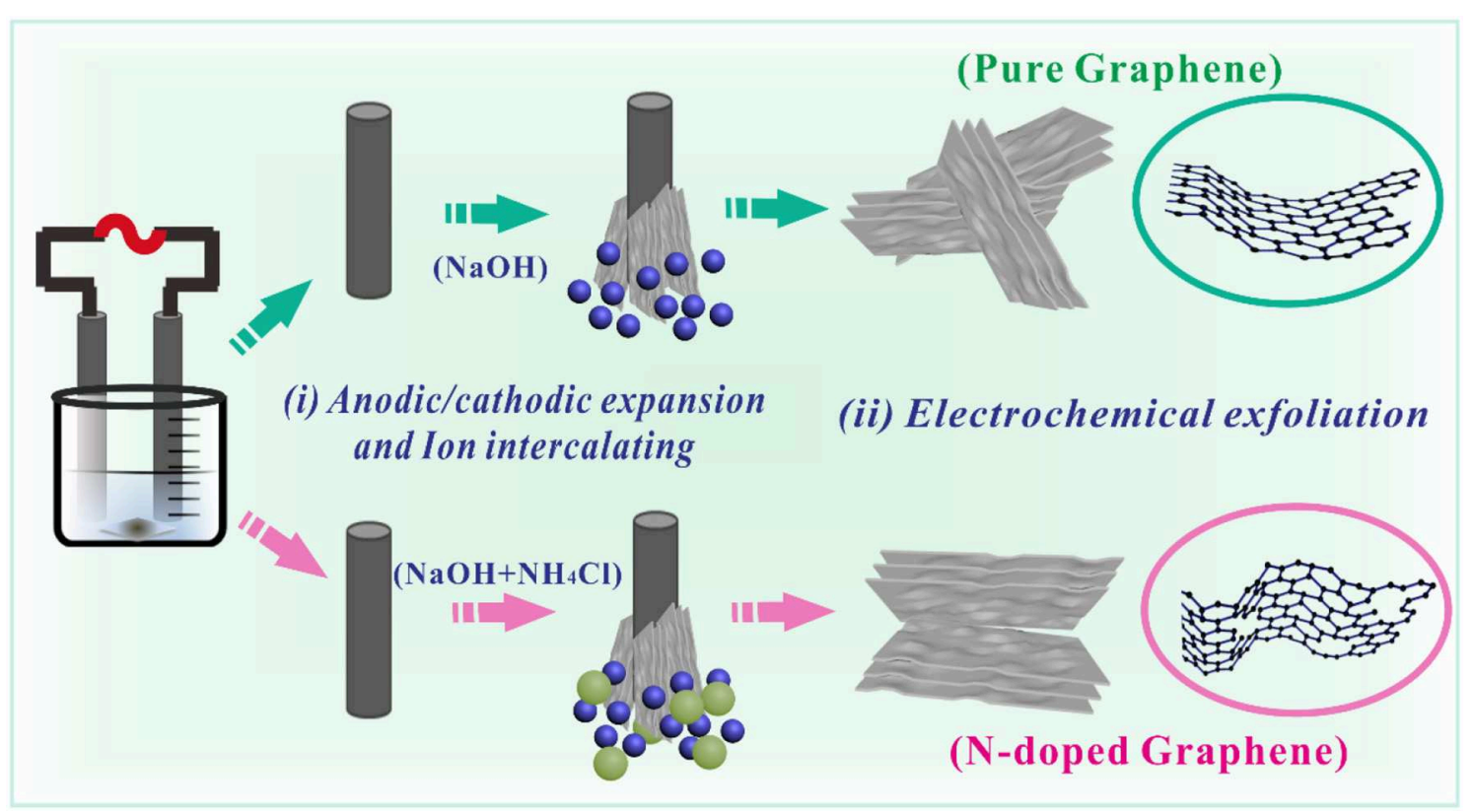

SCHEME 1 | The electrochemical formation of pure Gh and N-Gh samples.

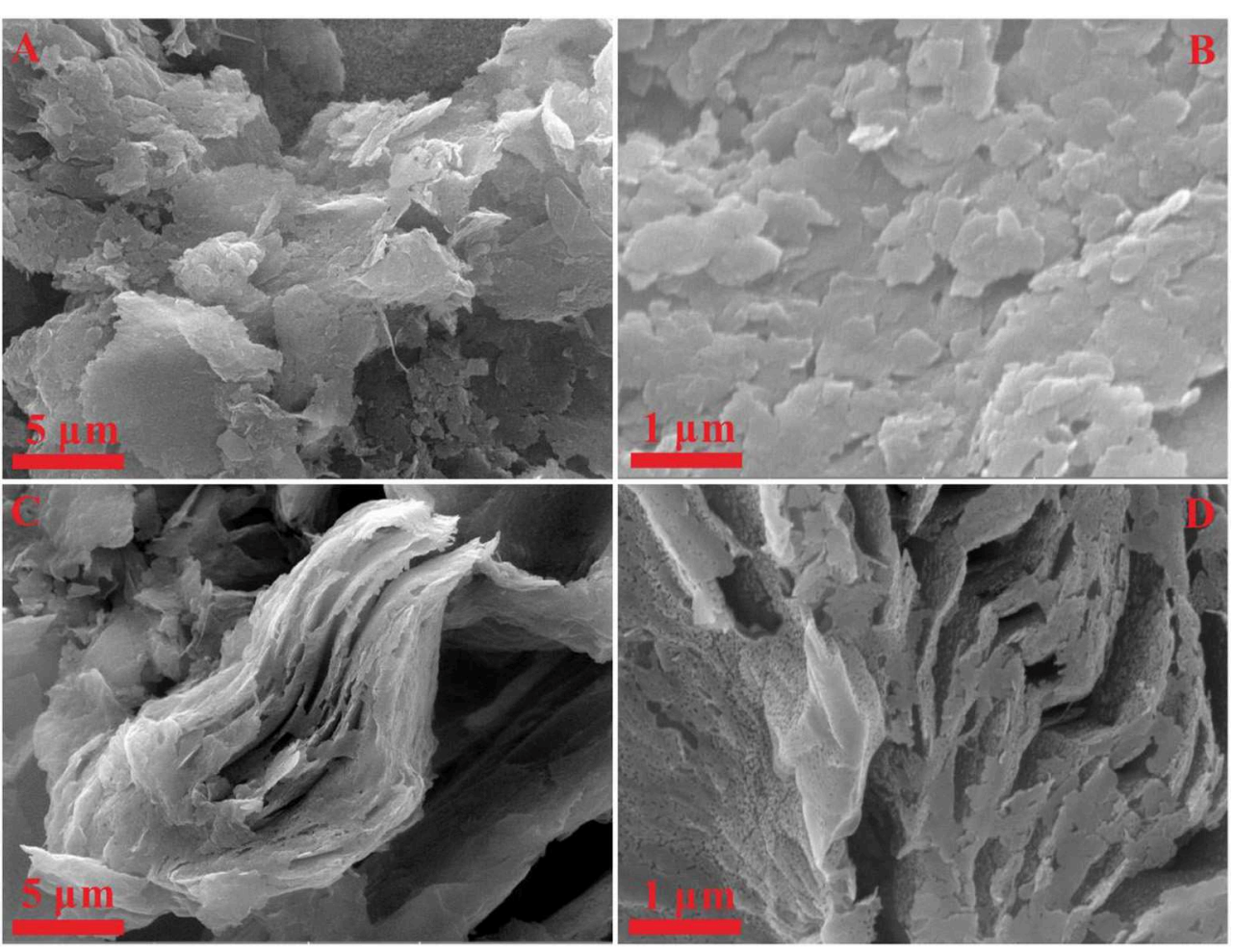

FIGURE 1 | (A,B) SEM images of pure Gh. (C,D) SEM images of N-Gh sample.

of materials using $\mathrm{KBr}$ as a reference. Thermogravimetric analysis (TGA, NETZSCH STA449F3) from 25 to $900^{\circ} \mathrm{C}$ was utilized to measure the thermostability of materials with a heating rate of $5^{\circ} \mathrm{C} \mathrm{min}^{-1}$ in air. Moreover, X-ray photoelectron Spectroscopy (XPS, ESCALab250) was tested to analyze the surface chemical composition of the asobtained samples with $\mathrm{C} 1 \mathrm{~s}$ photoelectron peak at $284.6 \mathrm{eV}$ as the reference. 

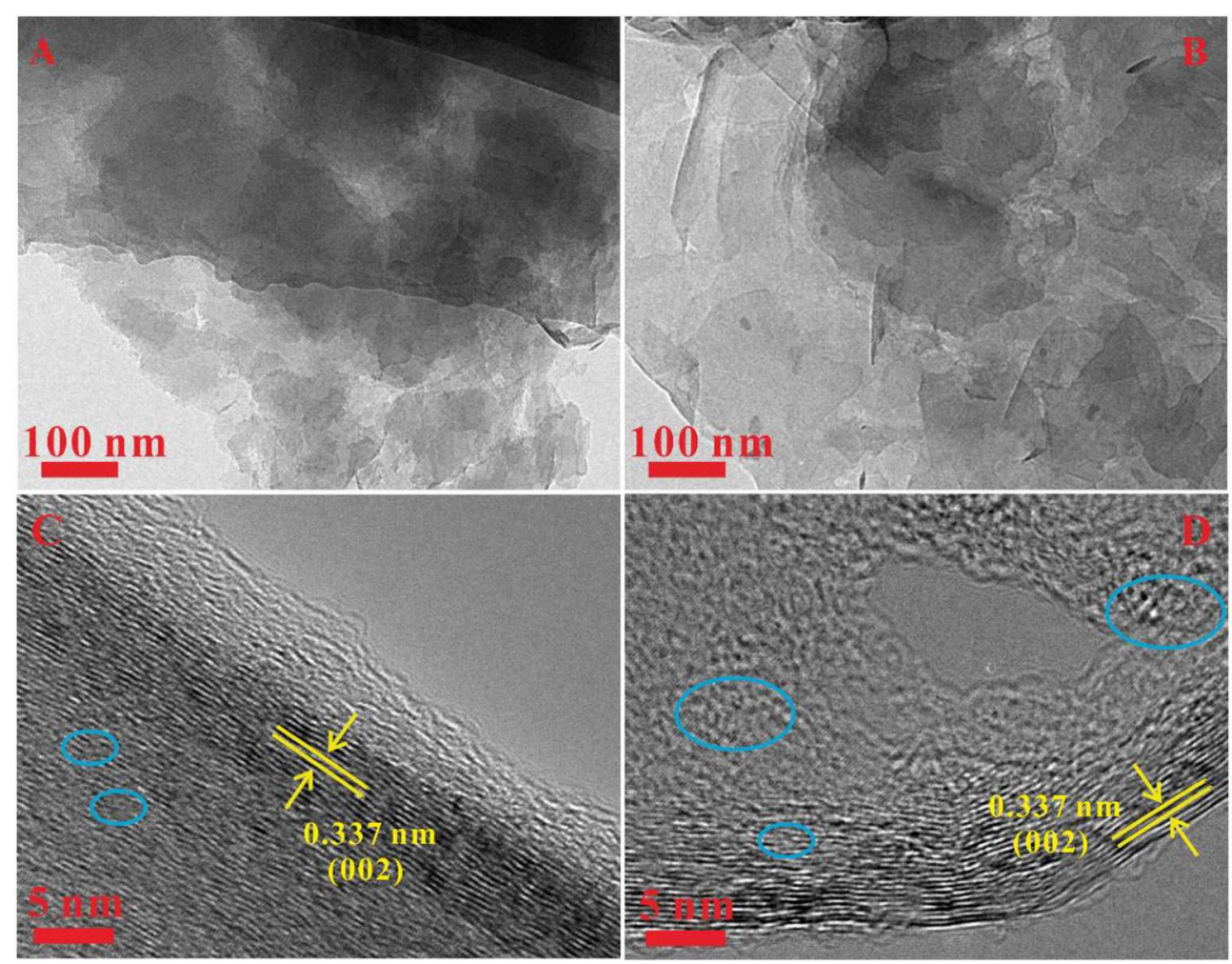

FIGURE 2 | (A,B) TEM images of the pure Gh and N-Gh samples. (C,D) HRTEM images of pure Gh and N-Gh samples.

\section{Electrochemical Measurement}

Active materials, super $\mathrm{P}$, and polyvinylidene fluoride (PVDF) were mixed in N-methyl-2-pyrrolidone (NMP) with a mass ratio of 80:10:10 to form a coating slurry. Then, the asobtained slurry was pressed onto a round nickel foam current collector. Finally, the electrodes with a loading mass of about $1.5 \mathrm{mg} \mathrm{cm}-2$ were formed through drying at $50^{\circ} \mathrm{C}$ in a vacuum overnight and pressing under a $10 \mathrm{MPa}$ pressure. A classic three-electrode electrochemical test system was utilized to investigate the electrochemical characteristics of the as-prepared materials. This test system was composed of a working electrode, platinum foil counter electrode, and $\mathrm{Hg} / \mathrm{HgO}$ reference electrode. It is worth noting that the working electrodes should be soaked in $2 \mathrm{M}$ $\mathrm{KOH}$ aqueous solution for $12 \mathrm{~h}$ before the electrochemical test. Moreover, the symmetric supercapacitor was equipped with two as-prepared working electrodes using $2 \mathrm{M} \mathrm{KOH}$ as an electrolyte solution and a glassy fibrous material as a separator. And the related calculation for the symmetric supercapacitor is based on the total mass of active material. Cyclic voltammetry (CV) curves were measured on MULTI AUTOLAB M204 (MAC90086) at various scanning rates. Electrochemical impedance measurements (EIS) were tested on a CHI 660B electrochemical working station with the frequency range between 100 and $0.01 \mathrm{~Hz}$. Galvanostatic discharge/charge files were investigated at room temperature on Land CT2001A battery cycler.

\section{RESULTS AND DISCUSSION \\ The Electrochemical Exfoliation via Alternating Voltage}

The electrochemical processes of the as-prepared Gh and N-Gh materials via alternating voltage electrochemical exfoliation have been displayed in Scheme 1. On the basis of previous reports (Wang et al., 2014; Jing et al., 2015), the surface of graphite electrodes were alternately oxidized and reduced during the electrochemical process of alternating voltage. Meanwhile, some cations and anions in the electrolyte solution can intercalate the layers of graphite to accelerate stripping speed. In detail, some defects and oxygen-containing functional groups on the surface of the graphite electrode have been induced during the anodic process. Then, some oxidized graphite was reduced via a cathodic reaction. In $\mathrm{NaOH}$ solution, the $\mathrm{Na}^{+}$and $\mathrm{OH}^{-}$can intercalate into the graphite layers. Certain amounts of hydrogen gas can be produced during the electrochemical process, which would promote the exfoliation rate of graphite. For the N-Gh sample, the addition of $\mathrm{NH}_{4}^{+}$and $\mathrm{Cl}^{-}$ions might be conducive to exfoliate the graphite electrode through much more intercalation. Moreover, the $\mathrm{Cl}^{-}$ions might be transformed into $\mathrm{ClO}^{-}$or $\mathrm{Cl}_{2}$ during the electrochemical anodic process (Munuera et al., 2017). The related oxidation-reduction of $\mathrm{NH}_{4}^{+}$also took place during alternate anodic and cathodic reactions, which could generate $\mathrm{C}-\mathrm{NH}_{2}$, - C-NH-C, and C-N- $\mathrm{C}_{2}$ functional groups. With the introduction of $\mathrm{NH}_{4} \mathrm{Cl}$ in the $\mathrm{NaOH}$ solution, the exfoliation 


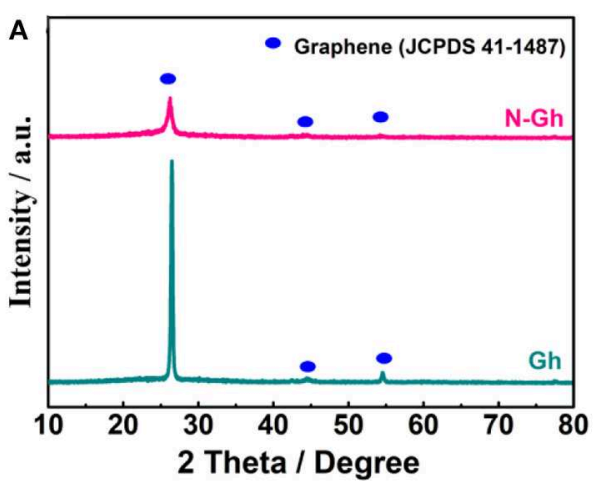

C

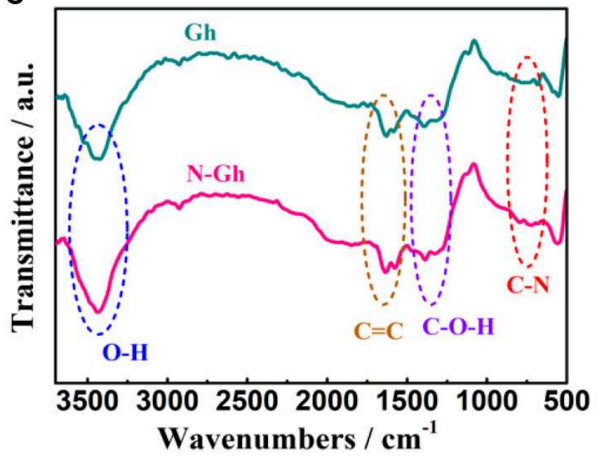

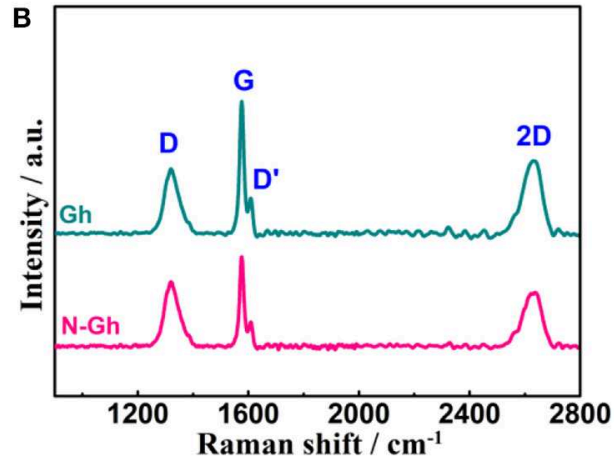

D

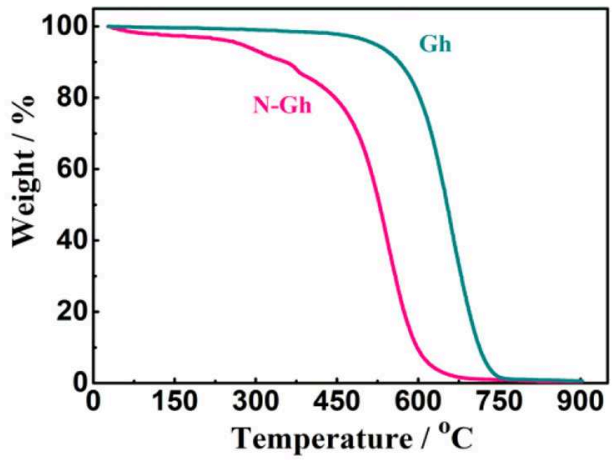

FIGURE 3 | (A) XRD patterns of pure Gh and N-Gh samples. (B) Raman spectra of pure Gh and N-Gh samples. (C) F-IR spectra of pure Gh and N-Gh samples. (D) TG curves of pure $\mathrm{Gh}$ and $\mathrm{N}-\mathrm{G}$ h samples.

rate can be effectively enhanced via alternating the voltage electrochemical process.

\section{The Microstructure, Morphology, and Composition of Samples}

The SEM has been utilized to analyze the morphologies of the as-prepared $\mathrm{Gh}$ and N-Gh, which is shown in Figure 1. As displayed in Figures 1A,B, the pure Gh sample presents thin flakes with various sizes $\left(0.5-5 \mu \mathrm{m}^{2}\right)$. In Figures 1C,D, the NGh displays porous thin sheets. It can also be seen that the size of N-Gh is much larger than that of pure Gh. Further, the characterization of the morphology has been measured using TEM, as shown in Figures 2A,C. These results reveal that the exfoliated $\mathrm{Gh}$ and N-Gh flakes typically feature some overlapping regions. Additionally, the HRTEM image of Gh (in Figure 2B) presents lattice spacing of $0.337 \mathrm{~nm}$, corresponding to (002) plane of graphene (Yang et al., 2014). In Figure 2C, a few defect-free and disorder domains can also be found in the as-obtained pure Gh. While the N-Gh sample exhibits a much more disordered structure and obvious pore structure in Figure 2D. The N-Gh prepared by alternating voltage exfoliation presents with a larger size and more defects than those of pure graphene, which might be due to the fast stripping and $\mathrm{N}$ doping processes.

Figure 3A presents the XRD powder pattern of pure Gh and N-Gh. The sharp peak of pure Gh at $26.4^{\circ}$ is indexed as (002) crystal plane of graphene (JCPDS Card no.41-1487). This sharp peak illustrates that the Gh maintains a high degree of crystallization and electrical conductivity (Xu et al., 2015). According to the results of contrasting the curves of pure Gh and N-Gh, the peak intensity of the N-Gh sample is obviously weaker, which is consistent with the HRTEM conclusion. The order/disorder structures and defects characterization of the asobtained materials have been further analyzed through Raman measurement, which is displayed in Figure 3B. The presence of $G$ band at $1,577 \mathrm{~cm}^{-1}$ is related to $E_{2 g}$ symmetry phonon mode, corresponding to ordered in-plane $\mathrm{sp}^{2}$ carbon atoms (Wang et al., 2017). The D band and D' shoulder band are at about 1,321 and $1,621 \mathrm{~cm}^{-1}$, respectively, which belong to the disorder in the carbon hexagons and edge carbons (Deng et al., 2011). Moreover, the $I_{2 D} / I_{G}$ and $I_{D} / I_{G}$ values of samples can typically reflect the number of layers and the degree of disorder structure, respectively (Soin et al., 2017). The $\mathrm{I}_{2 \mathrm{D}} / \mathrm{I}_{\mathrm{G}}$ values of pure Gh and N-Gh are 61.9 and $62.7 \%$, respectively, which could illustrate that the flakes of both samples have only a few layers. The $\mathrm{I}_{\mathrm{D}} / \mathrm{I}_{\mathrm{G}}$ value of $\mathrm{N}-\mathrm{Gh}$ is 0.71 , which is higher than that of pure $\mathrm{Gh}(0.57)$. This result again reveals that much more defects and disorder structure appear during the exfoliation process for N-Gh samples.

Furthermore, the surface functional groups of the as-obtained pure Gh and N-Gh have been detected via FT-IR spectrum analysis, as is displayed in Figure 3C. The large peaks at 3,432 $\mathrm{cm}^{-1}$ are related to $\mathrm{O}-\mathrm{H}$ bending from $\mathrm{H}_{2} \mathrm{O}$ (Wang $\mathrm{X}$. et al., 2018). The weak peaks from 1,639 to $1,579 \mathrm{~cm}^{-1}$ can be indexed to $\mathrm{sp}^{2}$-hybridized $\mathrm{C}=\mathrm{C}$ stretching in plane vibrations, which 


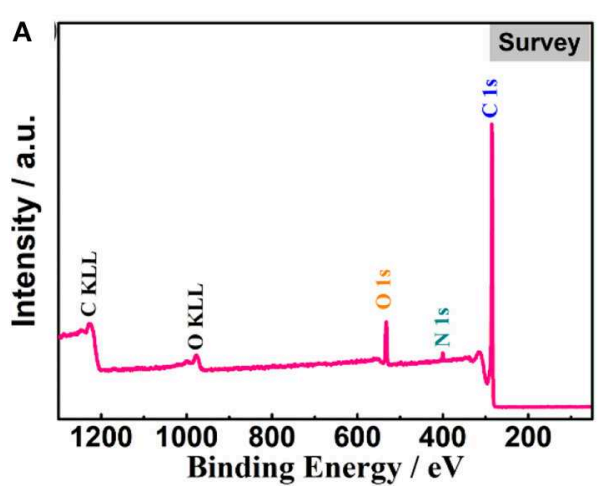

C

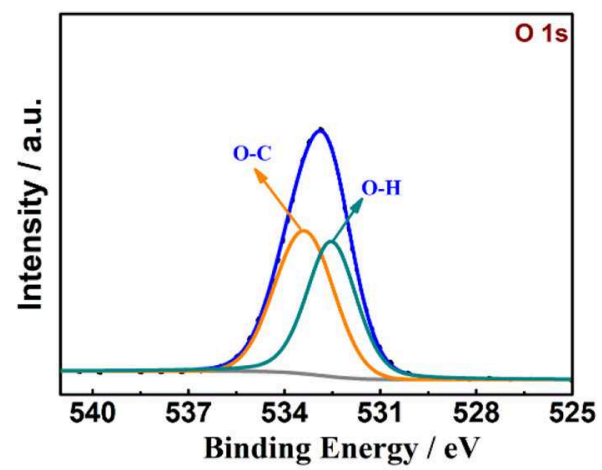

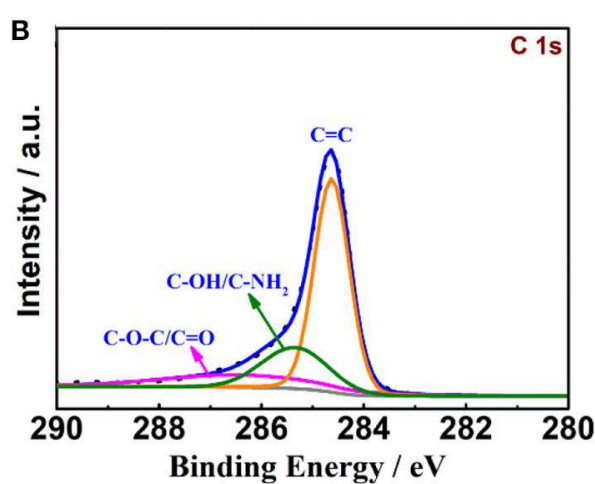

D

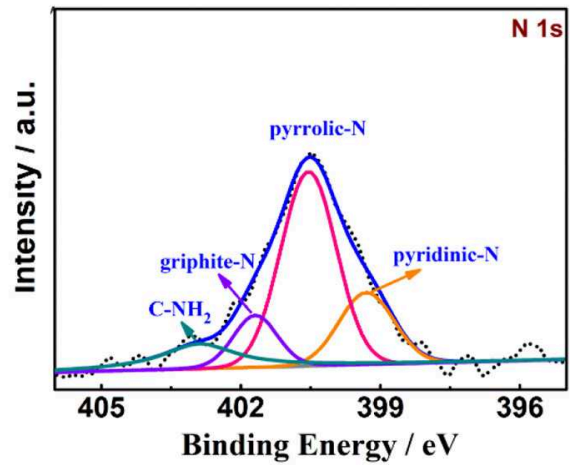

FIGURE 4 | XPS analysis of N-Gh material: (A) Full spectrum, (B) C 1 s spectrum, (C) 01 s spectrum, (D) N 1 s spectrum.
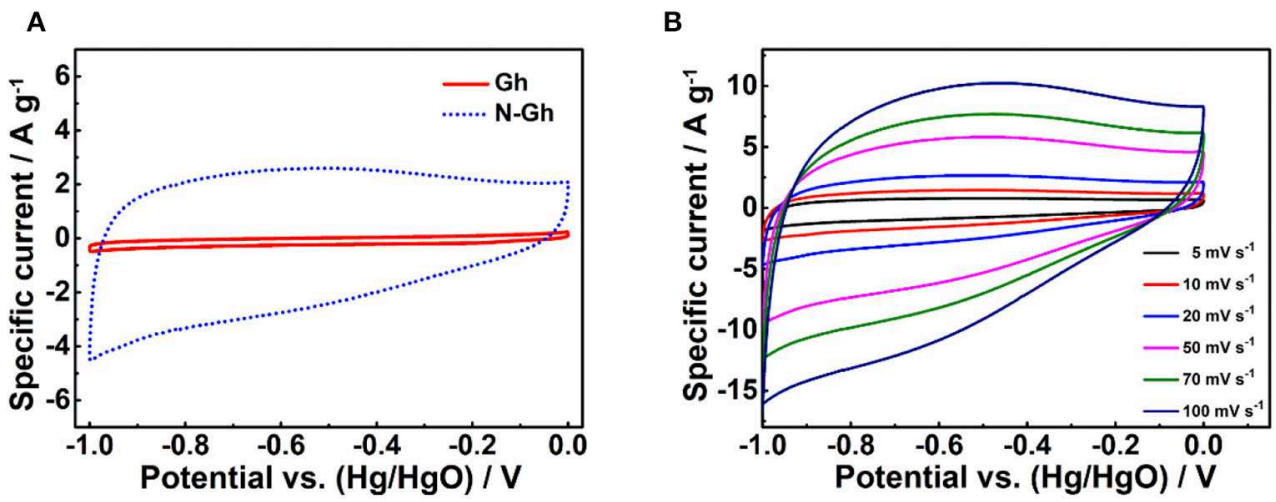

FIGURE 5 | (A) The CV files of pure Gh and N-Gh samples at a $10 \mathrm{mV} \mathrm{s}^{-1}$ based on a three-electrode system. (B) The CV curves of the as-prepared N-Gh under various scan rates from 5 to $100 \mathrm{mV} \mathrm{s}^{-1}$ based on a three-electrode system.

reveals the presence of the $\pi$-conjugation structure (Wang $\mathrm{X}$. et al., 2018; Lee et al., 2019). The weak peaks from 1,383 to $1,308 \mathrm{~cm}^{-1}$ correspond to oxygen-containing functional groups (C-O, C-OH, C-O-C) which illustrate the existence of a few hydroxyl/phenolic/alkoxy groups on the surface of the exfoliated Gh and N-Gh samples (Lee et al., 2019). A small peak at 728 $\mathrm{cm}^{-1}$ might correspond to C-N stretching (Islam et al., 2016), which indicates that $\mathrm{N}$ can be successfully doped in-situ during alternating voltage electrochemical exfoliation. In Figure 3D, the mass loss from 25 to $300^{\circ} \mathrm{C}$ of N-Gh might be mainly resulted from adsorbed water and coordinated water (Chen et al., 2020). Compared to the pure Gh, the TGA curve of N-Gh with the temperature from 300 to $700^{\circ} \mathrm{C}$ displays a quick downward trend, which illustrates the existence of much more defects and disorder structure in the as-obtained N-Gh sample (Xu et al., 2015).

The XPS spectra of N-Gh are displayed in Figure 4. As shown in Figure 4A, the $\mathrm{C}$, O, and $\mathrm{N}$ elements all lie in the asprepared N-Gh sample. The $\mathrm{N}$ atom content is $4.5 \%$ and the $\mathrm{O} / \mathrm{C}$ 

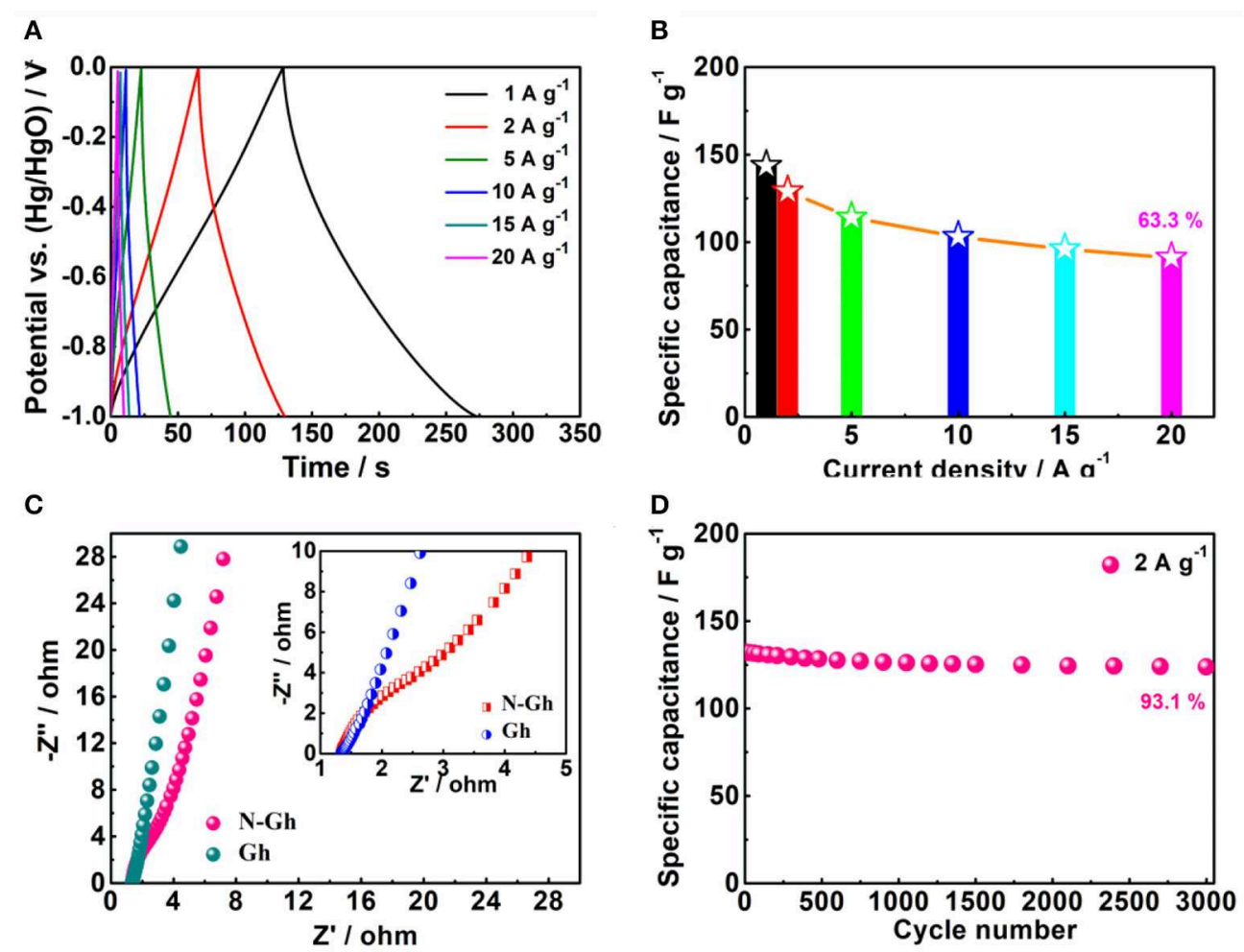

FIGURE 6 | (A) Galvanostatic charge-discharge files and (B) Specific capacities of the as-prepared N-Gh at various current densities from 1 to 20 A $\mathrm{g}^{-1}$ based on a three-electrode system. (C) Impedance spectroscopy plots of Gh and N-Gh in a three-electrode system (The inset is a larger version of the impedance spectroscopy plots). (D) Cycling stability of N-Gh at $2 \mathrm{~A} \mathrm{~g}^{-1}$ based on a three-electrode system.

atom ratio in this sample is 0.09 . Further, a dominant peak at $284.6 \mathrm{eV}$ is shown in the high-resolution XPS spectrum of C $1 \mathrm{~s}$ (Figure 4B), which is assigned to graphitic $\mathrm{C}=\mathrm{C}$ species, and the other two weak peaks at $285.5 \mathrm{eV}$ and $286.4 \mathrm{eV}$ correspond to $\mathrm{sp}^{3}$ carbons $\left(\mathrm{C}-\mathrm{OH} / \mathrm{C}-\mathrm{NH}_{2}\right)$ and oxygen carbons $(\mathrm{C}-\mathrm{O}-\mathrm{C} / \mathrm{C}=\mathrm{O})$, respectively (Wang et al., 2014). The $\mathrm{O} 1 \mathrm{~s}$ spectrum presents two peaks at 532.1 and $533.7 \mathrm{eV}$ in Figure 4C, which are related to $\mathrm{O}=\mathrm{C}$ and $\mathrm{O}-\mathrm{C}$, respectively (Hou et al., 2015; Bulusheva et al., 2017). A few oxygen-containing functional groups in the $\mathrm{N}$-Gh sample could be helpful to relieve overlapping. The $\mathrm{N}$ $1 \mathrm{~s}$ spectrum (in Figure 4D) has been fitted into four peaks at $399.3 \mathrm{eV}, 400.5 \mathrm{eV}, 401.7 \mathrm{eV}$, and $402.9 \mathrm{eV}$, which are assigned to pyridinic nitrogen (19.8\%), pyrrolic nitrogen (54.2\%), graphite nitrogen (11.9\%), and C- $\mathrm{NH}_{2}$ (14.1\%), respectively (Lee et al., 2014; Hong et al., 2019). These results again confirm that $\mathrm{N}$ has been successfully doped in N-Gh, which might contribute to the improvement of electrochemical performances.

\section{The Electrochemical Properties of Samples Based on a Three-Electrode System}

The electrochemical performances of pure Gh and N-Gh samples have been firstly explored using CV tests in $2 \mathrm{M} \mathrm{KOH}$ electrolyte solution with the voltage range from -1.0 to $0 \mathrm{~V}$ based on a threeelectrode system, which is shown in Figure 5A. It can be clearly seen that pure $\mathrm{Gh}$ and $\mathrm{N}-\mathrm{Gh}$ samples display rectangular $\mathrm{CV}$ curves, suggesting obvious electric double-layer storage behaviors (Munuera et al., 2017). The curve area of N-Gh is much larger than that of the pure Gh sample, which indicates the doping of $\mathrm{N}$ can obviously improve the specific capacity. Furthermore, the $\mathrm{CV}$ measurements of $\mathrm{N}-\mathrm{Gh}$ based on increased scan rates from 5 to $100 \mathrm{mV} \mathrm{s}^{-1}$ have been studied, as is revealed in Figure $5 \mathbf{B}$. The intensities of CV files increased with the increased scan rates, yet the shapes of curves remained broadly stable (Zhu et al., 2018; Tang et al., 2019). This result reveals that N-Gh might present good electrochemical reversibility.

Then, the charge-discharge files of the as-prepared N-Gh electrode in $2 \mathrm{M} \mathrm{KOH}$ electrolyte solution at various current densities are displayed in Figure 6A. Based on the specific capacitance formula $\left(\mathrm{C}_{\mathrm{s}}=\mathrm{It} / \mathrm{m} \Delta \mathrm{V}, \mathrm{F} \mathrm{g}^{-1}\right.$ ) (Wang Y. et al., 2018; Wei et al., 2019), the specific capacitances of N-Gh electrode at the current densities of $1,2,5,10,15$, and $20 \mathrm{~A} \mathrm{~g}^{-1}$ are 143.6, 129.1, 114.2, 103.2, 96.5, and 91.5 $\mathrm{F} \mathrm{g}^{-1}$, respectively, with high coulombic efficiency around $100 \%$, which is displayed in Figure 6B. Compared with the specific capacitance at $1 \mathrm{~A} \mathrm{~g}^{-1}$, the capacity retention rate is up to $63.7 \%$ even at $20 \mathrm{~A} \mathrm{~g}^{-1}$. This high rate behavior might be related to the existence defects and doping $\mathrm{N}$ in the $\mathrm{N}-\mathrm{Gh}$ sample. Moreover, the EIS curves of pure $\mathrm{Gh}$ and $\mathrm{N}-\mathrm{Gh}$ electrodes in $2 \mathrm{M} \mathrm{KOH}$ aqueous solution at their open voltages are shown in Figure 6C. Both samples present very small semicircles in the high frequency and high slope in 
A

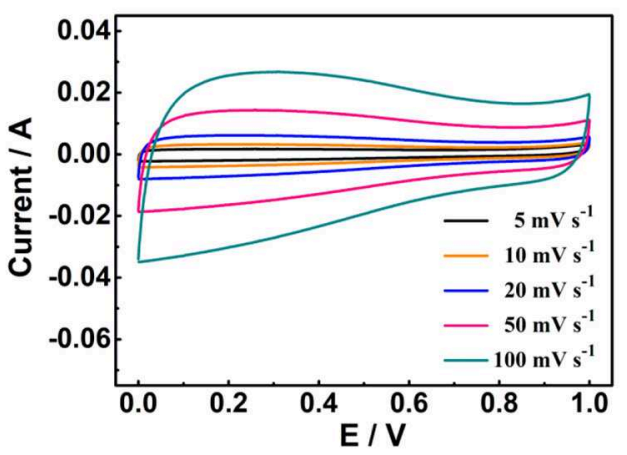

C

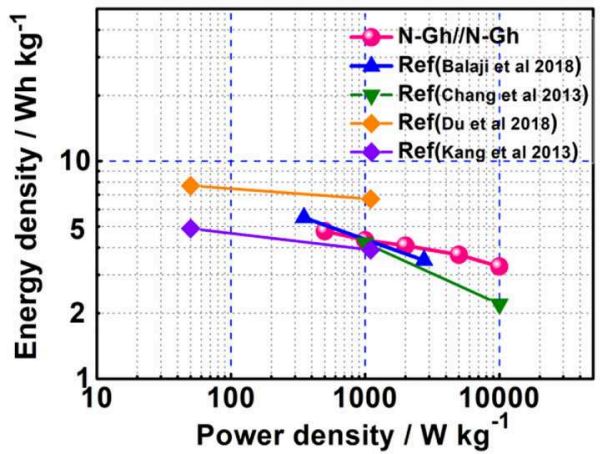

B

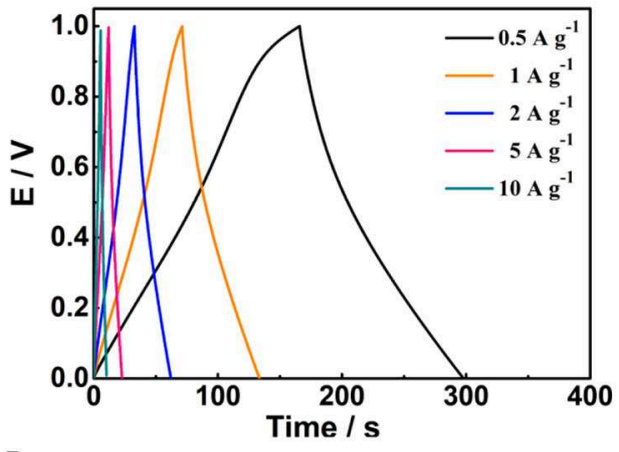

D

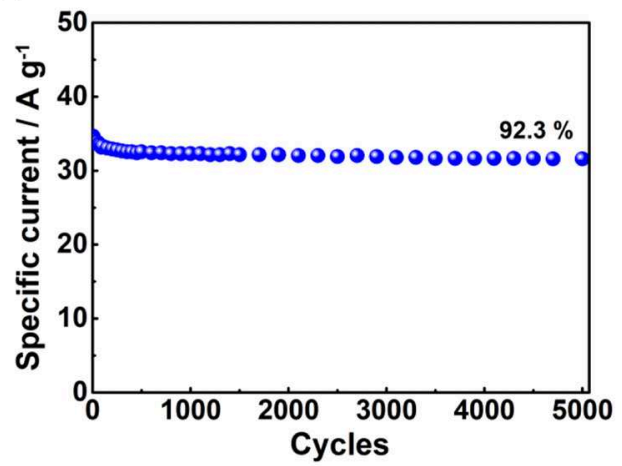

FIGURE 7 | (A) The CV files of N-Gh at various scan rates from 5 to $100 \mathrm{mV} \mathrm{s}^{-1}$ based on a two-electrode system. (B) Galvanostatic charge-discharge files of $\mathrm{N}-\mathrm{Gh} / / \mathrm{N}-\mathrm{Gh}$ with the current densities range from 1 to $20 \mathrm{~A} \mathrm{~g}^{-1}$. (C) Ragone plots of N-Gh//N-Gh. (D) Cycling stability of N-Gh//N-Gh at 0.5 A g ${ }^{-1}$.

the low frequency region, suggesting the pure Gh and N-Gh electrodes display high electrical conductivity and ion diffusion. The cycling stability of N-Gh electrodes have been investigated, which is displayed in Figure 6D. After 3,000 charge/discharge cycles in $\mathrm{KOH}$ aqueous solution, the specific capacity retention of $\mathrm{N}-\mathrm{Gh}$ is up to $93.1 \%$ at a current density of $2 \mathrm{~A} \mathrm{~g}^{-1}$. All these improved electrochemical performances could be derived from the structure of $\mathrm{N}-\mathrm{Gh}$ sample with $\mathrm{N}$ doping, which has few effects and a disordered structure.

\section{The Electrochemical Performances of N-Gh Based on a Two-Electrode System}

To better study the electrochemical capacity performances of the as-obtained N-Gh, the symmetric supercapacitor has been fabricated with two N-Gh electrodes. Figure 7A displays the $\mathrm{CV}$ curves of $\mathrm{N}-\mathrm{Gh} / \mathrm{N}-\mathrm{Gh}$ symmetric supercapacitor under the potential voltage from 0 to $1 \mathrm{~V}$ at different scan rates. It can be clearly seen that the shape of files stays the same as the scan rate increases (from 5 to $100 \mathrm{mV} \mathrm{s}^{-1}$ ), indicating the $\mathrm{N}-\mathrm{Gh} / \mathrm{N}-\mathrm{Gh}$ symmetric supercapacitor might display good electrochemical reversibility. The charge/discharge files of $\mathrm{N}$ $\mathrm{Gh} / \mathrm{N}-\mathrm{Gh}$ symmetric supercapacitor at the current densities between 0.5 and $10 \mathrm{~A} \mathrm{~g}^{-1}$ are revealed in Figure $7 \mathbf{B}$. The charge curves and discharge curves are almost symmetrical, revealing high columbic efficiency. Additionally, the specific capacities of the N-Gh//N-Gh symmetric supercapacitor have been calculated on the discharge files on the basis of the total mass of negative and positive electrode slices, as shown in Figure 7C. The specific capacities of the symmetric supercapacitor are $34.2,31.2,29.4$, 26.7, and $24.2 \mathrm{~F} \mathrm{~g}^{-1}$ at current densities of $0.5,1,2,5$, and $10 \mathrm{~A} \mathrm{~g}^{-1}$, respectively. The energy density of this symmetric supercapacitor is $4.76 \mathrm{Wh} \mathrm{kg}^{-1}$ at a power density of $500 \mathrm{~W} \mathrm{~kg}^{-1}$, and the retention ratio is up to $68.7 \%$ at the power density of $10,000 \mathrm{~W} \mathrm{~kg}^{-1}$. Compared with some other $\mathrm{N}$ doped carbonbased materials (in Figure 7C) (Chang et al., 2013; Kang et al., 2013; Balaji et al., 2018; Du et al., 2018), the energy density and rate behavior of $\mathrm{N}-\mathrm{Gh} / \mathrm{N}-\mathrm{Gh}$ is satisfactory. The cycling stability has been also investigated in Figure 7D, presenting with $92.3 \%$ retention of $\mathrm{N}-\mathrm{Gh} / \mathrm{N}-\mathrm{Gh}$ initial specific capacity after 5000 cycles. The perfect rate behavior and cycling stability of the $\mathrm{N}-\mathrm{Gh} / \mathrm{N}-\mathrm{Gh}$ symmetric supercapacitor further illustrates the asprepared N-Gh might be a promising material for various kinds of composites in supercapacitors.

\section{CONCLUSION}

In summary, the N-Gh sample has been prepared through an in-situ alternating voltage electrochemical exfoliation technique with the introduction of $\mathrm{NH}_{4} \mathrm{Cl}$ in to $\mathrm{NaOH}$ aqueous solution. The $\mathrm{N}$ chemical states in the $\mathrm{N}-\mathrm{Gh}$ sample mainly present pyrrolic nitrogen. Compared with the as-obtained pure Gh sample, the N-Gh shows a larger size, much more effects, and 
a disordered structure. Additionally, the related electrochemical behaviors have been investigated in a three-electrode aqueous solution system, indicating that $\mathrm{N}-\mathrm{Gh}$ displays a much higher specific capacity than that of pure Gh. Moreover, it also displays a good cycling stability and high rate behavior with $63.7 \%$ of the capacity retention rate even at a current density of $20 \mathrm{~A}$ $\mathrm{g}^{-1}$. All these good electrochemical characteristics of N-Gh could be ascribed to the doping $\mathrm{N}$, the existence of effects, and disorder structure, which is conducive to producing faradaic pseudocapacitance and reducing overlapping layers of graphene. The results of the symmetric supercapacitor fabricated with two N-Gh electrodes further illustrate the satisfactory cycling stability with $92.3 \%$ retention of $\mathrm{N}-\mathrm{Gh} / \mathrm{N}-\mathrm{Gh}$ initial specific capacity after 5,000 cycles. These insights illustrate that the $\mathrm{N}$ Gh sample prepared via an in-situ alternating voltage approach could have promising applications to construct composites for enhanced supercapacitors.

\section{DATA AVAILABILITY STATEMENT}

All datasets generated for this study are included in the article/supplementary material.

\section{REFERENCES}

Bakunin, E. S., Obraztsova, E. Y., and Rukhov, A. V. (2019). modern methods for synthesis of few-layer graphene structures by electrochemical exfoliation of graphite. Inorganic Mater. 10, 249-255. doi: 10.1134/S2075113319020047

Balaji, S. S., Karnan, M., and Sathish, M. (2018). Symmetric electrochemical supercapacitor performance evaluation of $\mathrm{N}$-doped graphene prepared via supercritical fluid processing. J. Solid State Electrochem. 22, 3821-3832. doi: $10.1007 /$ s10008-018-4086-9

Bu, F., Chen, W., Gu, J., Agboola, P. O., Al-Khalli, N. F., Shakir, I., et al. (2018). Microwave-assisted CVD-like synthesis of dispersed monolayer/fewlayer $\mathrm{N}$-doped graphene encapsulated metal nanocrystals for efficient electrocatalytic oxygen evolution. Chem. Sci. 9, 7009-7016. doi: 10.1039/C8SC0 $2444 \mathrm{H}$

Bulusheva, L. G., Kanygin, M. A., Arkhipov, V. E., Popov, K. M., Fedoseeva, Y. V., Smirnov, D. A., et al. (2017). In situ X-ray photoelectron spectroscopy study of lithium interaction with graphene and nitrogen-doped graphene films produced by chemical vapor deposition. J. Phys. Chem. C 121, 5108-5114. doi: 10.1021/acs.jpcc.6b12687

Chaban, V. V., and Prezhdo, O. V. (2015). Nitrogen-nitrogen bonds undermine stability of N-Doped graphene. J. Am. Chem. Soc. 137, 11688-11694. doi: $10.1021 /$ jacs.5b05890

Chang, Y., Han, G., Yuan, J., Fu, D., Liu, F., and Li, S. (2013). Using hydroxylamine as a reducer to prepare $\mathrm{N}$-doped graphene hydrogels used in high-performance energy storage. J. Power Sources 238, 492-500. doi: 10.1016/j.jpowsour.2013.04.074

Chen, K., Li, G., Wang, Y., Chen, W., and Mi, L. (2020). High loading FeS2 nanoparticles anchored on biomass-derived carbon tube as low cost and long cycle anode for sodium-ion batteries. Green Energy Environ. 5, 50-58. doi: 10.1016/j.gee.2019.11.001

Deng, D., Pan, X., Yu, L., Cui, Y., Jiang, Y., Qi, J., et al. (2011). Toward NDoped graphene via solvothermal synthesis. Chem. Mater. 23, 1188-1193. doi: $10.1021 / \mathrm{cm} 102666 \mathrm{r}$

Du, Y., Liu, L., Xiang, Y., and Zhang, Q. (2018). Enhanced electrochemical capacitance and oil-absorbability of $\mathrm{N}$-doped graphene aerogel by using aminofunctionalized silica as template and doping agent. J. Power Sources 379, 240-248. doi: 10.1016/j.jpowsour.2018.01.047

\section{AUTHOR CONTRIBUTIONS}

MJ and TW designed and engineered the samples, performed the experiments, and wrote the paper. All authors contributed to performing the data analysis and general discussion.

\section{FUNDING}

This work was supported by the National Natural Science Foundation of China (No. 21701044, 51625404), Postdoctoral Science Foundation Natural Science of China (No. 2019M662800), and Research Foundation of Education Bureau of Hunan Province, China (Grant no. 17A086).

\section{ACKNOWLEDGMENTS}

The authors also acknowledge the assistance on XPS measurements received from the Instrumental Analysis Center of Central South University.

Ejigu, A., Le Fevre, L. W., Fujisawa, K., Terrones, M., Forsyth, A. J., and Dryfe, R. A. W. (2019). Electrochemically exfoliated graphene electrode for highperformance rechargeable chloroaluminate and dual-ion batteries. ACS Appl. Mater. Interfaces 11, 23261-23270. doi: 10.1021/acsami.9b06528

Gong, X., Liu, G., Li, Y., Yu, D. Y. W., and Teoh, W. Y. (2016). Functionalized-graphene composites: fabrication and applications in sustainable energy and environment. Chem. Mater. 28, 8082-8118. doi: 10.1021/acs.chemmater.6b01447

Hong, W., Zhang, Y., Yang, L., Tian, Y., Ge, P., Hu, J., et al. (2019). Carbon quantum dot micelles tailored hollow carbon anode for fast potassium and sodium storage. Nano Energy 65:104038. doi: 10.1016/j.nanoen.2019.104038

Hou, H., Banks, C. E., Jing, M., Zhang, Y., and Ji, X. (2015). Carbon quantum dots and their derivative $3 \mathrm{D}$ porous carbon frameworks for sodium-ion batteries with ultralong cycle life. Adv. Mater. 27, 7861-7866. doi: 10.1002/adma.201503816

Islam, M. S., Mandal, B. H., Biswas, T. K., Rahman, M. L., Rashid, S. S., Tan, S.-H., et al. (2016). Poly(hydroxamic acid) functionalized copper catalyzed $\mathrm{C}-\mathrm{N}$ bond formation reactions. RSC Adv. 6, 56450-56457. doi: 10.1039/C6RA08155J

Jing, M., Wang, C., Hou, H., Wu, Z., Zhu, Y., Yang, Y., et al. (2015). Ultrafine nickel oxide quantum dots enbedded with few-layer exfoliative graphene for an asymmetric supercapacitor: enhanced capacitances by alternating voltage. J. Power Sources 298, 241-248. doi: 10.1016/j.jpowsour.2015.08.039

Kang, E., Jeon, G., and Kim, J. K. (2013). Free-standing, well-aligned ordered mesoporous carbon nanofibers on current collectors for high-power microsupercapacitors. Chem. Commun. 49, 6406-6408. doi: 10.1039/c3cc42436g

Lee, J., Noh, S., Pham, N. D., and Shim, J. H. (2019). Top-down synthesis of S-doped graphene nanosheets by electrochemical exfoliation of graphite: metal-free bifunctional catalysts for oxygen reduction and evolution reactions. Electrochim. Acta 313, 1-9. doi: 10.1016/j.electacta.2019.05.015

Lee, K. H., Oh, J., Son, J. G., Kim, H., and Lee, S.-S. (2014). Nitrogen-Doped graphene nanosheets from bulk graphite using microwave irradiation. ACS Appl. Mater. Interfaces 6, 6361-6368. doi: 10.1021/am405735c

Liu, W. W., and Wang, J. N. (2011). Direct exfoliation of graphene in organic solvents with addition of $\mathrm{NaOH}$. Chem. Commun. 47, 6888-6890. doi: $10.1039 / \mathrm{clcc} 11933 \mathrm{~h}$

Low, C. T. J., Walsh, F. C., Chakrabarti, M. H., Hashim, M. A., and Hussain, M. A. (2013). Electrochemical approaches to the production of 
graphene flakes and their potential applications. Carbon N. Y. 54, 1-21. doi: 10.1016/j.carbon.2012.11.030

Luo, G., Liu, L., Zhang, J., Li, G., Wang, B., and Zhao, J. (2013). Hole defects and nitrogen doping in graphene: implication for supercapacitor applications. ACS Appl. Mater. Interfaces 5, 11184-11193. doi: 10.1021/am403427h

Munuera, J. M., Paredes, J. I., Enterría, M., Pagán, A., Villar-Rodil, S., Pereira, M. F. R., et al. (2017). Electrochemical exfoliation of graphite in aqueous sodium halide electrolytes toward low oxygen content graphene for energy and environmental applications. ACS Appl. Mater. Interfaces 9, 24085-24099. doi: 10.1021/acsami.7b04802

Novoselov, K. S., Geim, A. K., Morozov, S. V., Jiang, D., Zhang, Y., Dubonos, S. V., et al. (2004). Electric field effect in atomically thin carbon films. Science 306, 666. doi: 10.1126/science.1102896

Parvez, K., Wu, Z.-S., Li, R., Liu, X., Graf, R., Feng, X., et al. (2014). Exfoliation of graphite into graphene in aqueous solutions of inorganic salts. J. Am. Chem. Soc. 136, 6083-6091. doi: 10.1021/ja5017156

Qu, L., Liu, Y., Baek, J.-B., and Dai, L. (2010). Nitrogen-doped graphene as efficient metal-free electrocatalyst for oxygen reduction in fuel cells. ACS Nano 4, 1321-1326. doi: 10.1021/nn901850u

Rao, K. S., Senthilnathan, J., Liu, Y.-F., and Yoshimura, M. (2014). Role of peroxide ions in formation of graphene nanosheets by electrochemical exfoliation of graphite. Sci. Rep. 4, 4237. doi: 10.1038/srep04237

Soin, N., Ray, S. C., Sarma, S., Mazumder, D., Sharma, S., Wang, Y.-F., et al. (2017). Tuning the Electronic and magnetic properties of nitrogen-functionalized few-layered graphene nanoflakes. J. Phys. Chem. C 121, 14073-14082. doi: 10.1021/acs.jpcc.7b01645

Suk, J. W., Kitt, A., Magnuson, C. W., Hao, Y., Ahmed, S., An, J., et al. (2011). Transfer of CVD-grown monolayer graphene onto arbitrary substrates. ACS Nano 5, 6916-6924. doi: 10.1021/nn201207c

Taheri Najafabadi, A., and Gyenge, E. (2015). Synergistic production of graphene microsheets by simultaneous anodic and cathodic electro-exfoliation of graphitic electrodes in aprotic ionic liquids. Carbon N. Y. 84, 449-459. doi: 10.1016/j.carbon.2014.12.041

Tang, T., Cui, S., Chen, W., Hou, H., and Mi, L. (2019). Bio-inspired nanoengineering of an ultrahigh loading 3D hierarchical $\mathrm{Ni@NiCo} \mathrm{S}_{4} / \mathrm{Ni}_{3} \mathrm{~S}_{2}$ electrode for high energy density supercapacitors. Nanoscale 11, 1728-1736. doi: 10.1039/C8NR09754B

Usachov, D., Vilkov, O., Gruneis, A., Haberer, D., Fedorov, A., Adamchuk, V. K., et al. (2011). Nitrogen-doped graphene: efficient growth, structure, and electronic properties. Nano Lett. 11, 5401-5407. doi: 10.1021/nl2031037

Wang, H., Maiyalagan, T., and Wang, X. (2012). Review on recent progress in nitrogen-doped graphene: synthesis, characterization, and its potential applications. ACS Catal. 2, 781-794. doi: 10.1021/cs200652y

Wang, H., Wei, C., Zhu, K., Zhang, Y., Gong, C., Guo, J., et al. (2017). Preparation of graphene sheets by electrochemical exfoliation of graphite in confined space and their application in transparent conductive films. ACS Appl. Mater. Interfaces 9, 34456-34466. doi: 10.1021/acsami.7b09891

Wang, P., Xiao, J., Guo, M., Xia, Y., Li, Z., and Huang, W. (2014). Preparation of graphite nanoflakes and supported noble metal/alloy nanoparticles by paired electrolysis with graphite electrodes. J. Electrochem. Soc. 161, H606-H611. doi: 10.1149/2.1211409jes

Wang, X., Ding, Y., Chen, F., Lu, H., Zhang, N., and Ma, M. (2018). Hierarchical porous $\mathrm{N}$-doped graphene monoliths for flexible solid-state supercapacitors with excellent cycle stability. ACS Appl. Energy Mater. 1, 5024-5032. doi: 10.1021/acsaem.8b01011

Wang, Y., Lu, Y., Chen, K., Cui, S., Chen, W., and Mi, L. (2018). Synergistic effect of Co3O4@C@MnO2 nanowire heterostructures for high-performance asymmetry supercapacitor with long cycle life. Electrochim. Acta 283, 1087-1094. doi: 10.1016/j.electacta.2018.06.163
Wei, W., Ye, W., Wang, J., Huang, C., Xiong, J.-B., Qiao, H., et al. (2019). Hydrangea-like $\alpha$-Ni1/3Co2/3(OH)2 reinforced by Ethyl Carbamate "Rivet" for all-solid-state supercapacitors with outstanding comprehensive performance. ACS Appl. Mater. Interfaces 11, 32269-32281. doi: $10.1021 /$ acsami.9b09555

Xu, J., Lin, Y., Connell, J. W., and Dai, L. (2015). Nitrogen-doped holey graphene as an anode for lithium-ion batteries with high volumetric energy density and long cycle life. Small 11, 6179-6185. doi: 10.1002/smll.2015 01848

Xu, Y., Zhang, C., Zhou, M., Fu, Q., Zhao, C., Wu, M., et al. (2018). Highly nitrogen doped carbon nanofibers with superior rate capability and cyclability for potassium ion batteries. Nat. Commun. 9:1720. doi: $10.1038 / \mathrm{s} 41467-018-04190-\mathrm{Z}$

Yang, S., Brüller, S., Wu, Z.-S., Liu, Z., Parvez, K., Dong, R., et al. (2015). Organic radical-assisted electrochemical exfoliation for the scalable production of high-quality graphene. J. Am. Chem. Soc. 137, 13927-13932. doi: 10.1021/jacs.5b09000

Yang, W., Chen, G., Shi, Z., Liu, C.-C., Zhang, L., Xie, G., et al. (2013). Epitaxial growth of single-domain graphene on hexagonal boron nitride. Nat. Mater. 12, 792-797. doi: 10.1038/nmat3695

Yang, Y., Lu, F., Zhou, Z., Song, W., Chen, Q., and Ji, X. (2013). Electrochemically cathodic exfoliation of graphene sheets in room temperature ionic liquids N-butyl, methylpyrrolidinium bis(trifluoromethylsulfonyl)imide and their electrochemical properties. Electrochim. Acta 113, 9-16. doi: 10.1016/j.electacta.2013.09.031

Yang, Y., Qiao, B., Yang, X., Fang, L., Pan, C., Song, W., et al. (2014). Lithium titanate tailored by cathodically induced graphene for an ultrafast lithium ion battery. Adv. Funct. Mater. 24, 4349-4356. doi: 10.1002/adfm.2013 04263

Yang, Y., Shi, W., Zhang, R., Luan, C., Zeng, Q., Wang, C., et al. (2016). Electrochemical exfoliation of graphite into nitrogen-doped graphene in glycine solution and its energy storage properties. Electrochim. Acta 204, 100-107. doi: 10.1016/j.electacta.2016.04.063

Yi, M., and Shen, Z. (2015). A review on mechanical exfoliation for the scalable production of graphene. J. Mater. Chem. A 3, 11700-11715. doi: $10.1039 /$ C5TA00252D

Zabihi, O., Ahmadi, M., Li, Q., Fakhrhoseini, S.M., Komeily Nia, Z., Arjmand, M., et al. (2019). Simultaneous electrochemical-assisted exfoliation and in situ surface functionalization towards large-scale production of few-layer graphene. FlatChem 18:100132. doi: 10.1016/j.flatc.2019.100132

Zhang, C., Fu, L., Liu, N., Liu, M., Wang, Y., and Liu, Z. (2011). Synthesis of nitrogen-doped graphene using embedded carbon and nitrogen sources. Adv. Mater. 23, 1020-1024. doi: 10.1002/adma.201004110

Zhu, Y., Huang, Z., Hu, Z., Xi, L., Ji, X., and Liu, Y. (2018). 3D interconnected ultrathin cobalt selenide nanosheets as cathode materials for hybrid supercapacitors. Electrochim. Acta 269, 30-37. doi: $10.1016 /$ j.electacta.2018.02.146

Conflict of Interest: The authors declare that the research was conducted in the absence of any commercial or financial relationships that could be construed as a potential conflict of interest.

Copyright (c) 2020 Jing, Wu, Zhou, Li and Liu. This is an open-access article distributed under the terms of the Creative Commons Attribution License (CC BY). The use, distribution or reproduction in other forums is permitted, provided the original author(s) and the copyright owner(s) are credited and that the original publication in this journal is cited, in accordance with accepted academic practice. No use, distribution or reproduction is permitted which does not comply with these terms. 